\title{
HCCI Octane Number Scale in a Pressure-Temperature Diagram
}

\section{- A Tool for Investigating Combustion Behavior of Practical Fuels}

\author{
J. Masurier, A. Elkhazraji, A. Mohammed, B. Johansson \\ King Abdullah University of Science and Technology (KAUST), \\ Clean Combustion Research Center (CCRC), \\ Thuwal, 23955-6900, Saudi Arabia)
}

\section{Abstract}

A new approach for investigating combustion behavior of practical fuels under homogeneous charge compression ignition (HCCI) conditions was developed with the help of a cooperative fuel research (CFR) engine. The method uses a set of two pressure-temperature diagrams and two charts, each with an octane number scale based on primary reference fuels (PRF), created from experimental results by sweeping the intake temperature. The two pressure-temperature diagrams report conditions leading to the start of the low temperature combustion and the start of the main combustion, respectively. Additional two charts -- required compression ratio and fraction of low temperature heat release charts -- describe global combustion behavior and the importance of the low temperature combustion. Each diagram and chart, together with their respective octane number scale, allow to examine the combustion behavior of practical fuels by comparing their combustion behavior with those of the PRFs. Finally, octane numbers representing the various combustion behaviors of a practical fuel can be rated. Application of the method with two low-octane number surrogate fuels led to the following main results. The required compression ratio chart provides a quick description of the combustion behavior. The pressure-temperature diagrams indicate the ease with which a fuel ignites under low temperature combustion and main combustion regimes. An extra pressure-temperature diagram reports start and end of the negative temperature coefficient regime and highlights that this regime is independent of the fuel. Accordingly, each combustion regime is clearly defined in the pressure-temperature diagram. The fraction of low temperature heat release finally indicates how low temperature combustion vanishes. Finally, octane numbers for each practical fuel were rated from each diagram and chart. Rated octane numbers suggest that a single PRF cannot reflect the entire combustion behavior of a practical fuel; but multiple PRFs are required for HCCI combustion.

\section{Introduction}

Now more than ever, the development of highefficiency spark ignition (SI) engines requires increased engine compression ratio and efficiently combusting fuel, preferably high-octane fuel with a well-controlled combustion process. The limiting factor in the development of such engines is the autoignition of the end-gases, known as knock. This undesired autoignition occurs in the unburnt gases located in front of the flame propagation when conditions of pressure, temperature and mixture are reached, and it can seriously damage the engine. Mitigating this undesired phenomenon is therefore of major importance [1,2].

Octane number is a metric that reflects how much a practical fuel is prone to knock: the higher the octane number, the more resistant the fuel is to knock. Two octane numbers, the research octane number (RON) [3] and the motor octane number (MON) [4], have rated fuel knock for nearly a century; they represent two extreme combustion behaviors for a fuel, covering the entire operating range of an SI engine. A cooperative fuel research (CFR) engine rates RON 
and $\mathrm{MON}$ at specific conditions. $\mathrm{RON}$ is rated at low temperature and low rotation speeds $\left(52{ }^{\circ} \mathrm{C}\right.$ and 600 rpm); while $\mathrm{MON}$ is rated at high temperature and high rotation speeds $\left(149{ }^{\circ} \mathrm{C}\right.$ and $\left.900 \mathrm{rpm}\right)$. For each rating, the octane number of a practical fuel is provided by the primary reference fuel (PRF) generating the same knock intensity. PRF is a binary mixture of n-heptane and isooctane, and the volumetric fraction of isooctane equals the octane number. N-heptane and isooctane therefore introduce a scale from 0 to 100 , where 100 reflects a fuel that is highly-resistant to knock. With modern downsized and down-speeded SI engines that tend to operate beyond RON and MON conditions [1], these octane numbers have become nearly obsolete.

Over the past years, new indexes have been proposed to further describe combustion behavior of fuels (both SI and HCCI) under a wide range of conditions, and to replace RON and MON [5-8]. The octane index (OI) -- particularly that introduced by Kalghatgi -- has received considerable attention [5]. $\mathrm{OI}$ is defined from RON and MON as OI $=\mathrm{RON}-$ KS where $\mathrm{S}$ corresponds to the sensitivity of the fuel ( $\mathrm{RON}-\mathrm{MON}$ ), and $\mathrm{K}$ is a weighing factor reflecting the pressure-temperature history of the air/fuel mixture. OI is therefore an extension of RON and MON in which the factor $\mathrm{K}$ indicates whether conditions are beyond $(\mathrm{K}<0$ or $\mathrm{K}>1)$, equal to $(\mathrm{K}$ $=0$ for $\mathrm{RON}$ and $\mathrm{K}=1$ for $\mathrm{MON})$ or between $(0<\mathrm{K}$ $<1)$ RON and MON conditions. Finally, the OI suggests that two fuels with the same OI and the same pressure-temperature history autoignite the same, and most recent OI results show that ternary mixtures of toluene/n-heptane/isooctane are better for matching OI [9]. The definition of the octane number, regardless of the operating conditions, should be revised by including such mixtures as initiated by Hauber et al. [6]. However, despite the high potential of OI, this index lacks a description of the combustion behavior of fuels over the entire operating range of the engines [10,11].

Recent research on understanding combustion behavior, conducted by Szybist et al. [10] and Splitter et al. [12], introduced the pressuretemperature diagram as a tool for predicting the endgases autoignition of air/fuel mixtures -- and therefore -- the occurrence of knock. Their method consisted of using the pressure-temperature history

Page 2 of 22

$10 / 19 / 2016$ of the unburnt air/fuel mixture in the combustion chamber, together with ignition delays computed from detailed mechanisms. However, extraction of the experimental data related to the end-gases is complex, requiring at least a two-zone model [13]. Moreover, the use of ignition delays is questionable as they are time-resolved, while engine data are crank-resolved. As a result, a model of the thermodynamic conditions of the end gases, together with the ignition delays, indicates that end-gas autoignition may be affected by the low temperature combustion process (exothermic reactions starting before the main combustion), while no clear occurrence is observed from the experiments [14]. Nonetheless, this approach is gaining increased attention [15-17].

To identify the conditions at which autoignition occurs for a given air/fuel mixture in SI without interference from flame propagation, stoichiometric autoignition experiments should be conducted. However, the excessive pressure gradient could result in the breakdown of the engine; so, instead of running at stoichiometric conditions, understanding fuel combustion behavior could be achieved by running with very lean mixtures, i.e. running under homogeneous charge compression ignition [18-21]. Such an approach, with the pressure-temperature diagram, was conducted by the authors [22,23]. Results showed that running HCCI experiments can help identify the conditions at which autoignition occurs in an engine for a given fuel; but for a greater understanding of the practical fuel autoignition, an octane number scale is required.

The aim of this study is to develop an octane number scale for the pressure-temperature diagram through the use of primary reference fuel (PRF), mixtures of n-heptane and isooctane. Such a scale would clarify the combustion behavior of fuels over different combustion regimes, as well as the role of the octane number. In addition to the pressure-temperature diagram, two charts will elaborate on these findings. These pressure-temperature diagrams and additional charts provide good understanding of the octane number of a practical fuel and its combustion behavior over a wide range of conditions. 


\section{Experimental setup}

Table 1: Characteristics of the CFR engine.

\begin{tabular}{lll}
\hline \hline Parameter & Unit & Value \\
\hline \hline Displaced volume & $\mathrm{cc}$ & 611.7 \\
Stroke & $\mathrm{mm}$ & 114.3 \\
Bore & $\mathrm{mm}$ & 82.55 \\
Connecting rod & $\mathrm{mm}$ & 256 \\
Compression ratio & - & $4: 1$ to $18: 0$ \\
Number of valves & - & 2 \\
Exhaust valve opening & $\mathrm{CA}$ ATDC & 140 \\
Exhaust valve closure & $\mathrm{CA}$ ATDC & -345 \\
Inlet valve opening & $\mathrm{CA}$ ATDC & -350 \\
Inlet valve closure & $\mathrm{CA}$ ATDC & -146 \\
Coolant water temperature & ${ }^{\circ} \mathrm{C}$ & $100 \pm 1.5$ \\
Oil temperature & ${ }^{\circ} \mathrm{C}$ & $57 \pm 8$ \\
\hline \hline
\end{tabular}

All the experiments were conducted using a single cylinder variable compression ratio Waukesha cooperative fuel research (CFR) engine. Table 1 itemizes the main characteristics of the CFR engine. The original intake manifold of the CFR engine was modified to operate in HCCI mode; the carburetor, designed to run with stoichiometric, or close to stoichiometric air/fuel mixtures, was replaced by a port fuel injector. The port fuel injector was placed adjacent to the intake valve to allow the engine to cover a wide range of air/fuel mixtures, especially the very lean air/fuel mixtures required for HCCI. The entire intake pipe was also replaced, and two heaters were included to allow the CFR engine to operate with intake temperatures from $25^{\circ} \mathrm{C}$ to 200 ${ }^{\circ} \mathrm{C}$. The first heater was set in the center of the intake pipe, well upstream from the intake valve to warm the air flow. The second heater, set around the intake pipe, maintained a constant, well distributed temperature. The intake pressure ranged from $0.5 \mathrm{bar}$ to 1.3 bar and depends on the air flow controlled by a Brooks mass flow controller with respect to the intake pressure setpoint. The mass flow controller handled air flow from 0 to 1000 slpm, with accuracy of $\pm 0.5 \%$ of the flow rate and $\pm 0.1 \%$ of the full scale. Finally, the air/fuel mixture, or equivalence ratio, was measured with the help of a Bronkhorst liquid flowmeter, set on the fuel line and controlled by adjusting the pulse width of the port fuel injector. The flowmeter provides flow measurements from 0 to $2 \mathrm{~L} / \mathrm{h}$ with accuracy of $\pm 0.5 \%$ of the flow rate and $\pm 0.1 \%$ of the full scale. A schematic representation of the experimental setup is shown in Figure 1.

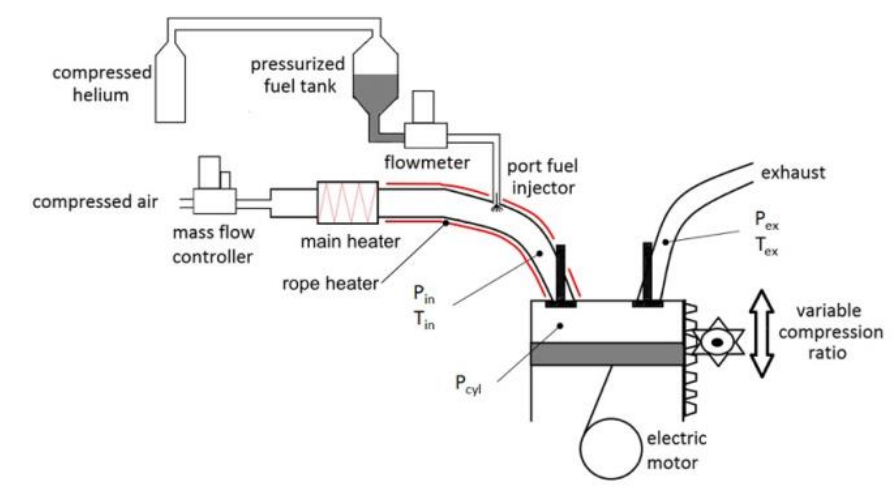

Figure 1: Scheme of the experimental setup.

The standard detonation pickup sensor (placed on one side of the combustion chamber and originally used to monitor knock intensity), was replaced with an AVL QC34D piezo-electric pressure transducer to monitor the in-cylinder pressure sensor. This pressure transducer detects in-cylinder pressure up to 150 bar, with an accuracy of $\pm 0.3 \%$ of the full scale. In addition, intake and exhaust pressures are monitored with two AVL LP11DA absolute pressure transducers, one in each pipe. These pressure transducers measure pressure from 0 to 10 bar with an accuracy of $\pm 0.1 \%$ of the full scale. Finally, an AVL 365C encoder with a resolution of 0.2 crank angle is used to find the traces of the different pressures during the cycle. In addition to pressure traces, intake and exhaust temperatures are recorded for every cycle, with the help of K-type thermocouples with an accuracy of $\pm 2 \mathrm{~K}$. A total of 200 consecutive cycles were recorded for each operating point and post-processed through a typical thermodynamic analysis [24]. Details of the complete post-processing procedure are available in Appendix 1.

\section{Methodology}

The first aim of this study is to develop an octane number $(\mathrm{ON})$ scale into the pressure-temperature diagram. As for RON and MON, this ON scale is based on analysis of the respective combustion behavior of primary reference fuels (PRFs). The ON of a practical fuel can be assigned by comparing its combustion behavior with the combustion behavior of PRFs within the same pressure-temperature diagram. In addition to the pressure-temperature 
diagram, the study also examines $\mathrm{ON}$ from two additional approaches. The first approach is based on the compression ratio required with respect to the intake temperature, since the compression ratio is a critical parameter for $\mathrm{ON}$ rating $[3,4]$, and for the experimental protocol described below. The second approach is an add-on analysis to the pressuretemperature diagram which analyzes the fraction of low temperature heat release, since PRFs easily exhibit such a heat release.

The experimental protocol for each fuel tested consists of a sweep of the intake temperature from 25 ${ }^{\circ} \mathrm{C}$ to $200{ }^{\circ} \mathrm{C}$, while a fixed combustion phasing located at the top dead center is maintained by adjusting the compression ratio of the CFR engine. In previous studies by the authors [22,23], combustion phasing was represented by CA50, the crank angle at which $50 \%$ of the total energy is released. In the present study, combustion phasing is represented by the crank angle of the high temperature heat release peak to ensure a wellcontrolled and suitable combustion, even for fuels exhibiting significant low temperature heat release. In fact, a significant low temperature heat release moves CA50 earlier than the high temperature heat release and could result in less combustion stability, or misfire. The rest of the parameters were kept fixed during operations. Intake pressure was fixed at 1 bar to represent naturally aspirated conditions. Equivalence ratio was fixed at 0.3 to operate at very lean HCCI conditions. Rotation speed was fixed at $600 \mathrm{rpm}$ to allow enough time for autoignition and combustion to take place, as HCCI combustion mode is governed by kinetics which is time-resolved. Finally, for repeatability, each operating point was performed three times by switching the injection on and off.

For the results, compression ratios and intake temperatures were direct parameters obtained from the experiments, and they depend on the fuel. Other results were obtained by analyzing the average heat release rate traces, based on 200 consecutive cycles and computed from in-cylinder pressure traces. A total of four different points were captured from each average heat release rate to describe the combustion behavior; Figure 2 shows the definition of those points. The onset of low temperature combustion $\left(\mathrm{SOC}_{\mathrm{L}}\right)$ was captured when a threshold of $0.5 \mathrm{~J} / \mathrm{CA}$

Page 4 of 22

$10 / 19 / 2016$ was reached. This threshold was selected to avoid tracking the onset of the combustion as combustion noise. Similarly, $\mathrm{SOC}_{\mathrm{M}}$ represents the onset of main combustion and it was captured at $5 \mathrm{~J} / \mathrm{CA}$. This threshold was selected to ensure the capture of the onset of main combustion such that the same definition can be used with or without low temperature heat release. Indeed, in case of significant heat release rate at the end of the low temperature heat release, an onset of main combustion can be observed and compared with the other fuels. Then, LTCP and LTCM were captured respectively, as the peak of the low temperature heat release and inflection point that separates low temperature heat release from high temperature heat release. Those points also allow the different regimes of combustion to be divided: the low temperature combustion bounded by $\mathrm{SOC}_{\mathrm{L}}$ and $\mathrm{LTC}_{\mathrm{P}}$, the negative temperature coefficient bounded by LTCP and $\mathrm{LTC}_{\mathrm{M}}$ and the main combustion bounded by $\mathrm{LTC}_{\mathrm{M}}$ and the end of combustion. It is worth noting that the main combustion here can be split into an intermediate temperature heat release and a high temperature heat release [25] separated by SOCM. Nonetheless, the definition of $\mathrm{SOC}_{\mathrm{M}}$ cannot be considered as a clear divider of those regimes due to its above definition. Therefore, only the main combustion is considered for the discussion on the results. Once identified, all those points were reported on the respective pressure-temperature trace into the pressure-temperature diagram. It is notable that combustion without low temperature heat release might occur in some fuels under some conditions. For such cases, only SOCs points, at 0.5 $\mathrm{J} / \mathrm{CA}$ and $5 \mathrm{~J} / \mathrm{CA}$ respectively, were studied, and only the main combustion regime was considered. Finally, the fraction of low temperature heat release (an extra parameter to analyze with the pressuretemperature diagram), was obtained as the ratio of energy released from $\mathrm{SOC}_{\mathrm{L}}$ to $\mathrm{LTC}_{\mathrm{M}}$ over the total energy released from $\mathrm{SOC}_{\mathrm{L}}$ to the end of combustion, and it was detected during the expansion stroke, when the heat release rate reached $0.5 \mathrm{~J} / \mathrm{CA}$. 


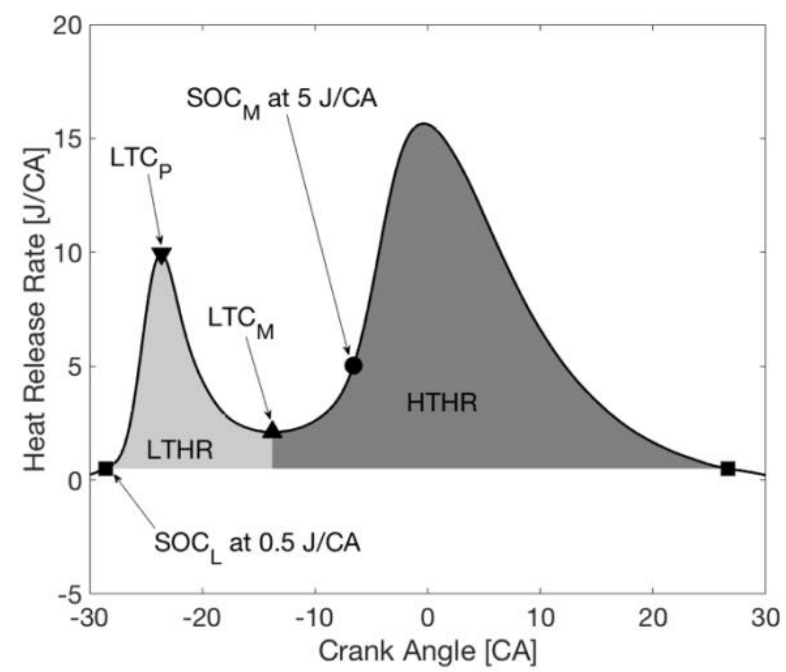

Figure 2: Definition of parameters extracted from average heat release rate trace. $S O C_{L}$ corresponds to start of combustion for low temperature heat release. LTCP corresponds to peak of low temperature combustion. $L T C_{M}$ corresponds to inflection point between low temperature combustion and main combustion. SOCM corresponds to start of combustion for high temperature heat release/main combustion. LTHR corresponds to energy released during low temperature combustion and HTHR corresponds to energy released during the main combustion. Together, LTHR and HTHR represent total energy released by combustion.

\section{Results and Discussion}

The development of an octane number (ON) scale, with respect to the methodology was addressed first with the help of six primary reference fuels (PRFs). Those results were then used with two well-known low octane number surrogate fuels, representative of practical fuels, to emphasize the potential of this $\mathrm{ON}$ scale.

\section{Octane number scale}

\section{Compression ratio requirement}

The octane number $(\mathrm{ON})$ originates from $\mathrm{RON}$ and MON tests in which PRFs (binary mixtures of nheptane and isooctane) are used as the ON scale. By definition, $\mathrm{ON}$ equals the volumetric fraction of isooctane into the PRF, resulting in a 0 (neat nheptane) to 100 (neat isooctane) ON scale, and the ON of a practical fuel is provided by a PRF with the same behavior. Nonetheless, discussions on RON and MON do not emphasize the critical nature of the compression ratio in the CFR engine; it is a critical parameter which must be adjusted to validate $\mathrm{ON}$ tests and it can be used to directly rate ON. Similarly, PRFs were used in the present study to develop an
ON scale; and the compression ratio was adjusted according to the experimental protocol defined. A total of six PRFs, equally distributed between 0 to 100, were selected to build the octane number. Each PRF was separately tested by adjusting the compression ratio of the CFR engine for different intake temperatures in order to maintain combustion phasing around the top dead center. The required compression ratio (directly from the experiments), with respect to the intake temperature and fuel, could be used as a first approach to investigating the octane number. Results are shown in Figure 3.

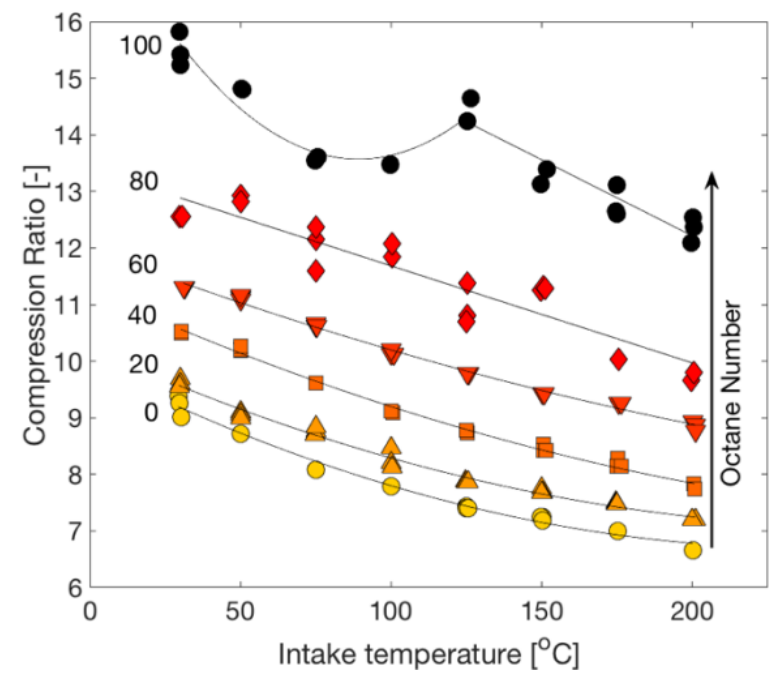

Figure 3. Compression ratio required with respect to intake temperature for primary reference fuels tested. Numbers on left indicate corresponding primary reference fuel and octane number.

The intake temperature chart in Figure 3 indicates the ease with which a given fuel autoignites. The lower the required compression ratio, the easier the fuel autoignites, and vice-versa: the higher the required compression ratio, the more difficult fuel autoignition becomes. Independent of intake temperature, PRFs expectedly autoignite with respect to their ON, PRF0 is the easiest to autoignite and PRF100 is the most difficult. With respect to intake temperature, compression ratio trends monotonically decrease for all fuels except isooctane (PRF100). Because HCCI combustion is governed by kinetics, and kinetics rise when boosted by high temperatures, those trends were expected. Moreover, compression ratio trends for all the PRFs tested from PRF0 to PRF80 can be fitted with second order polynomial trends. In the case of PRF100, the compression ratio first decreases until almost $100{ }^{\circ} \mathrm{C}$ with a second order fitting trend. Then, the compression ratio increases during the transition 
from $100{ }^{\circ} \mathrm{C}$ to $125^{\circ} \mathrm{C}$; finally it decreases linearly for higher intake temperature than $125^{\circ} \mathrm{C}$. To further understand the origin of those different trends -especially for PRF100 -- a closer look at the heat release traces is necessary.

Figures 4 to 6 show heat release rate traces respectively for PRF0, PRF80 and PRF100 as fuels, and for four different intake temperatures. N-heptane combustion easily exhibits two-stages of combustion with a significant release of low temperature heat. PRF80 manifests a similar behavior to that of PRF0, but with a less intense low temperature heat release. Finally, PRF100 exhibits two-stage combustion at both $50{ }^{\circ} \mathrm{C}$ and $100{ }^{\circ} \mathrm{C}$ intake temperatures, but with less low temperature heat release than PRF 80; while for $150{ }^{\circ} \mathrm{C}$ and $200{ }^{\circ} \mathrm{C}$ intake temperature, low temperature heat release vanishes. Low temperature heat release originates from exothermic reactions, which contribute to a temperature rise that in turn promotes the main combustion. Because low temperature heat release vanishes at some point for PRF100, a higher compression ratio is required to compensate the boosting temperature usually provided by low temperature heat release. Finally, the second order fitting curves observed in Figure 3 clearly explains the presence of low temperature heat release, while the linear trend observed for PRF100 from $125{ }^{\circ} \mathrm{C}$ to $200{ }^{\circ} \mathrm{C}$ is caused by a lack of low temperature heat release. The compression ratio intake temperature chart can be used to quickly describe the combustion behavior of a fuel without requiring lengthy analysis. The octane number of a practical fuel might be determined with respect to the intake temperature using this chart. Besides, the trend of the required compression ratio could indicate the presence and significance of low temperature heat release when it occurs. Finally, the required compression ratio is a global parameter that represents the entire combustion behavior.

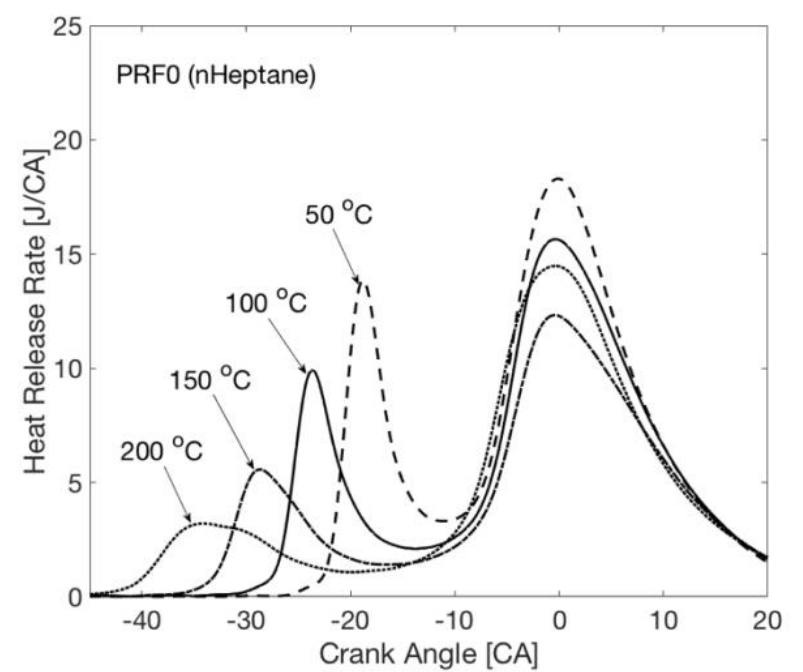

Figure 4: Heat release rate traces with respect to crank angle for PRFO (neat n-heptane) as fuel and for four different intake temperatures.

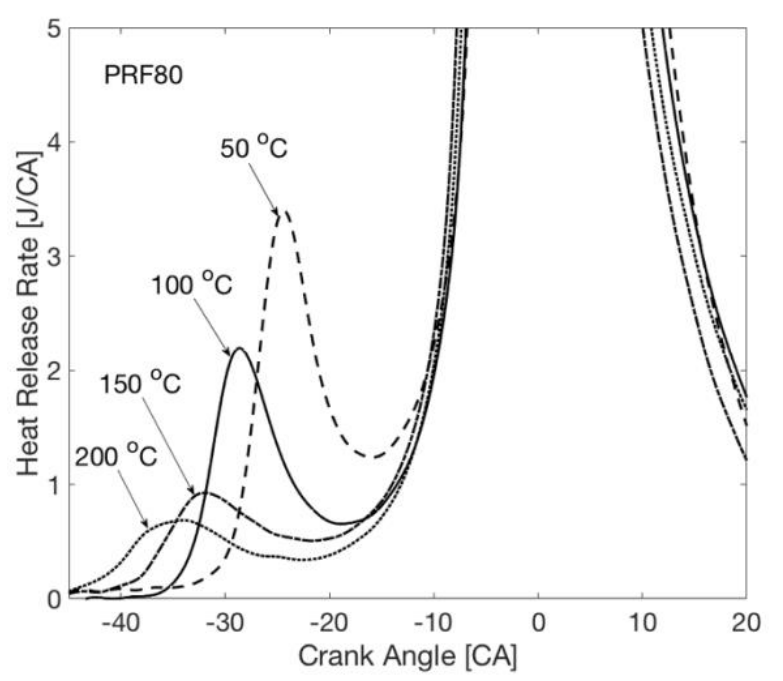

Figure 5: Heat release rate traces with respect to crank angle for PRF80 (80\% isooctane and 20\% n-heptane) as fuel and for four different intake temperatures. 


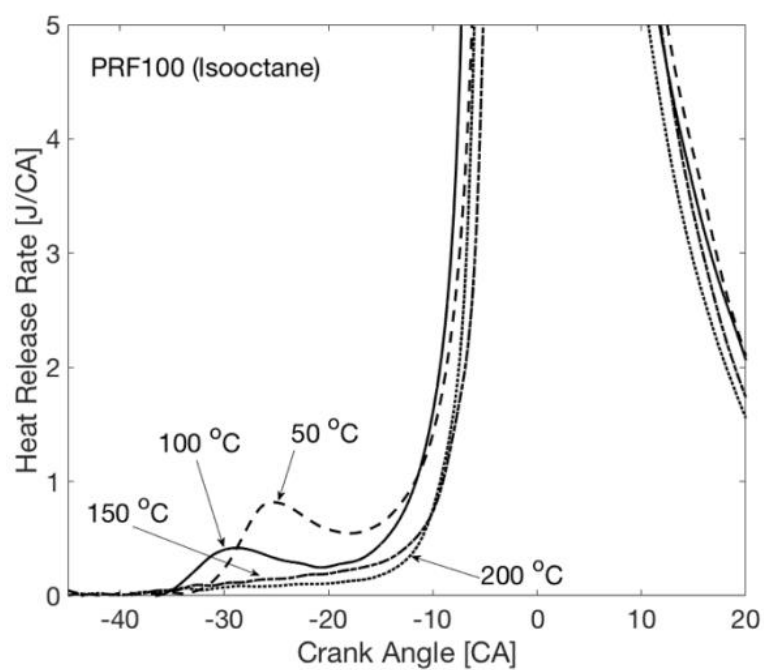

Figure 6: Heat release rate traces with respect to crank angle for PRF100 (neat isooctane) as fuel and for four different intake temperatures.

\section{Pressure-Temperature diagram}

The present study develops an $\mathrm{ON}$ scale into the pressure-temperature diagram to provide a comprehensive understanding of fuel behavior, while the compression ratio - intake temperature chart offers a quick, broad observation. The pressuretemperature diagram details the starting conditions leading to the different combustion regimes (low temperature combustion, the negative temperature coefficient and the main combustion). The pressuretemperature diagram uses pressure-temperature history where key points, captured from the heat release rate trace, are reported. These heat release rate traces of the selected PRFs were further analyzed and the key points defined in the methodology section were reported on the respective pressuretemperature traces. Results for each PRF are presented in Figures 7 to 12. Observing the trends for $S_{S O C}$ with PRF0, the dependence of autoignition on the pressure and temperature is clearly visible. Initially, at an intake temperature of $25{ }^{\circ} \mathrm{C}$, a high pressure and low temperature within the combustion chamber are required. As soon as the intake temperature increases, autoignition occurs with a lower pressure, but with a higher temperature, showing that autoignition depends on both pressure and temperature in the experimental range covered. Nevertheless, change in the trends could be expected, as per PRF100 results discussed below. The other key points for n-heptane, LTCP, LTCM and $\mathrm{SOC}_{\mathrm{M}}$, follow similar trends to these of $\mathrm{SOC}_{\mathrm{L}}$, but each regime of combustion differs with an increase in intake temperature. The gap along the pressuretemperature traces (corresponding to the low temperature combustion) progressively reduces due to the intensity of the low temperature heat release, which decreases with the rise in intake temperature (Figure 4). This reduction in low temperature heat release is related to both the amount of fuel injected and the in-cylinder pressure during the cycle, which are less with higher intake temperatures. The amount of fuel reduces because the equivalence ratio was kept constant while the in-cylinder pressure is less because the mass inducted was less and the compression ratio decreased to keep the same phasing. It is very likely that at some point, $\mathrm{SOC}_{\mathrm{L}}$ and LTCP will overlap and no further low temperature combustion would occur. The negative temperature coefficient, limited by the gap between LTC points, is quite fixed over the range of intake temperature investigated; but because they are closely related, as soon as the low temperature combustion disappears, the negative temperature coefficient could also disappear. Finally, the occurrence of the main combustion, represented by the gap along the pressure-temperature trace from $\mathrm{LTC}_{\mathrm{M}}$ to $\mathrm{SOC}_{\mathrm{M}}$, is faster during low intake temperatures, and it progressively slows. The intensity of the low temperature heat release, and the amount of fuel injected into the combustion chamber, are mainly responsible for this trend. All the PRFs, up to PRF80, follow identical trends and the same conclusions can be drawn as for PRF0. In PRF100, a change in behavior is clearly observed. First, all the points captured from the heat release rate trace for low intake temperatures $\left(25^{\circ} \mathrm{C}\right.$ to $\left.75{ }^{\circ} \mathrm{C}\right)$ behave much like other PRFs tested. Then, the low temperature combustion and the negative temperature combustion vanish; but traces of low temperature combustion remain until the trend of $\mathrm{SOC}_{\mathrm{L}}$ evolves in parallel with the trend of $\mathrm{SOC}_{\mathrm{M}}$ (starting around $125^{\circ} \mathrm{C}$ ). 


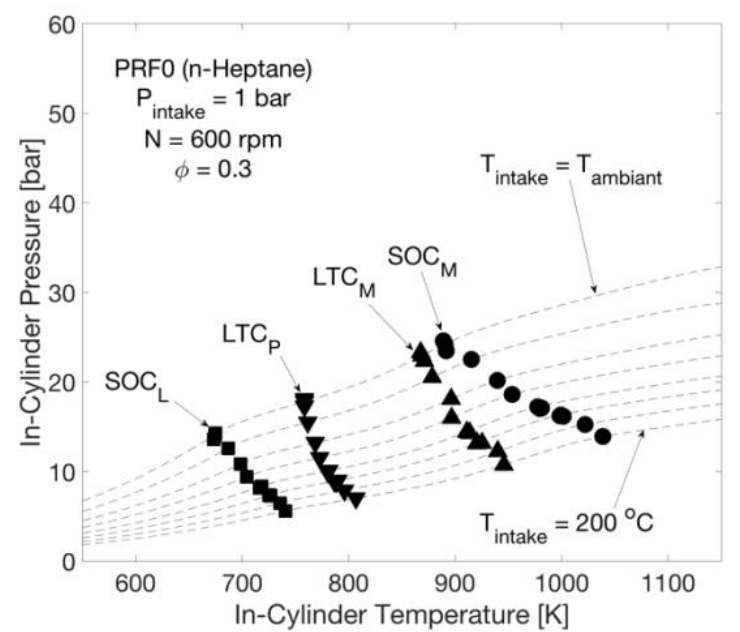

Figure 7: Pressure-temperature diagram for PRFO (n-heptane) as fuel.

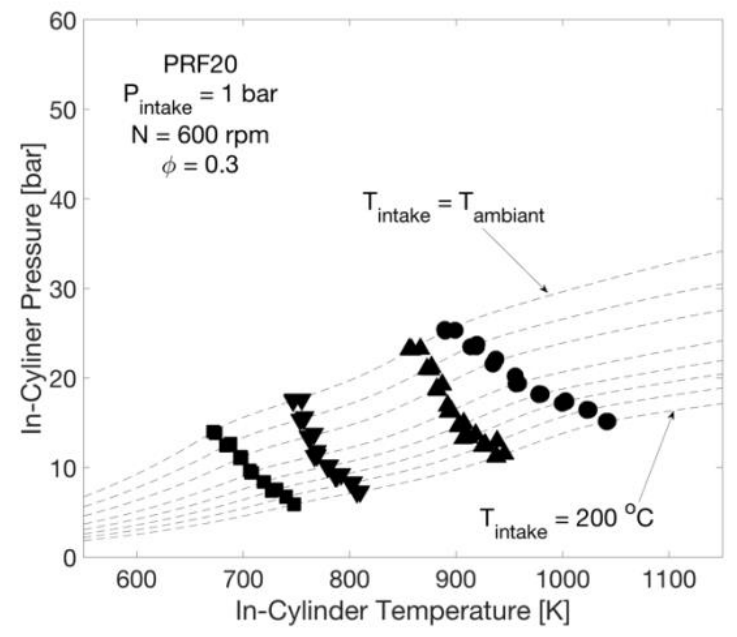

Figure 8: Pressure-temperature diagram for PRF20 as fuel.

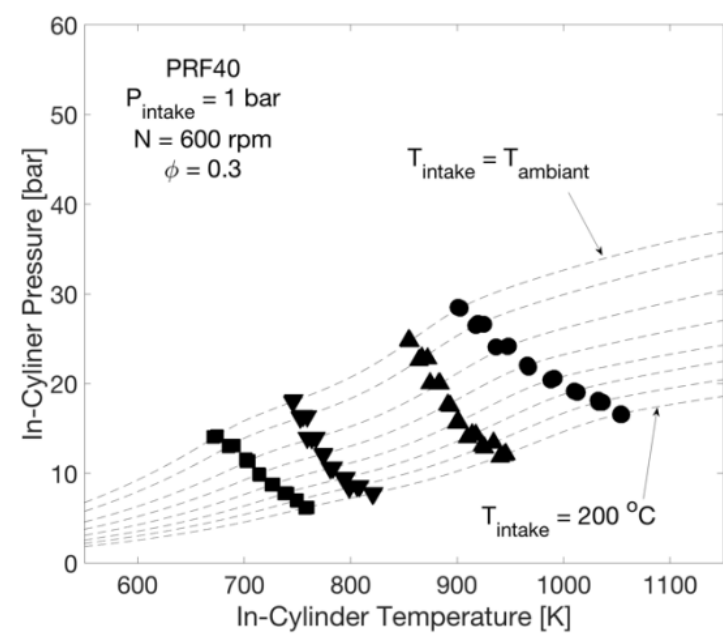

Figure 9: Pressure-temperature diagram for PRF40 as fuel.

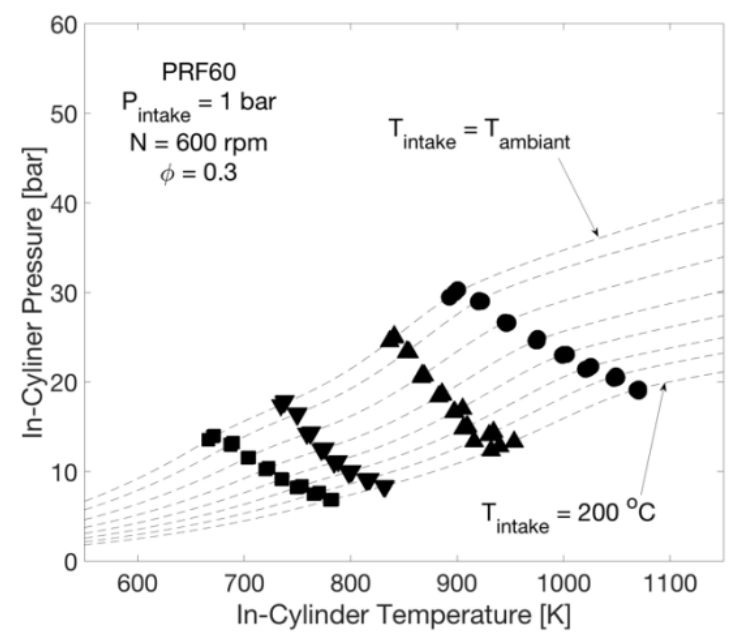

Figure 10: Pressure-temperature diagram for PRF60 as fuel.

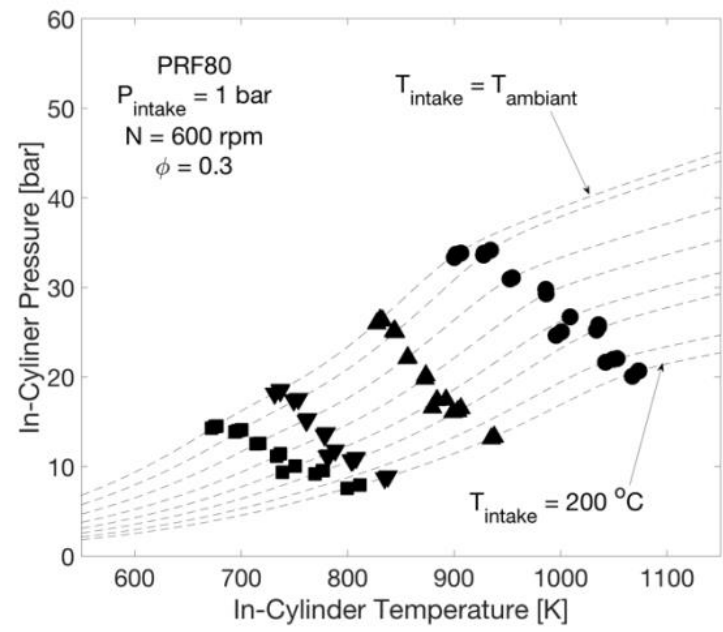

Figure 11: Pressure-temperature diagram for PRF80 as fuel.

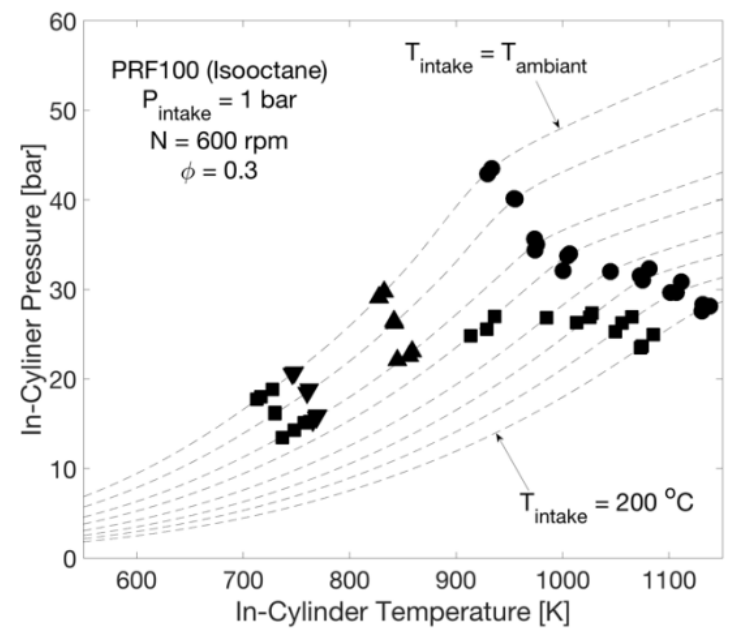

Figure 12: Pressure-temperature diagram for PRF100 (isooctane) as fuel.

Page 8 of 22

$10 / 19 / 2016$ 
Finally, all the results for each PRF are taken together to generate the $\mathrm{ON}$ scale into the pressuretemperature diagram. However, due to the occurrence of different combustion regimes, emphasized by the key points, the ON scale must be split into multiple pressure-temperature diagrams -at least one for each key point -- for clarification and future use. It notable that the scale of each of those pressure-temperature diagrams has been adjusted to provide a accurate observation of the results. All the results for $\mathrm{LTC}_{\mathrm{P}}$ and $\mathrm{LTC}_{\mathrm{M}}$ are presented in Figure 13. Both LTCP and LTCM collapse, meaning that the negative temperature coefficient domain is independent of the ON but could vanish at some point with respect to the ON. Moreover, trends for LTCP and LTCM evolve in parallel, meaning that the negative temperature coefficient domain is fixed and a low temperature combustion regime will appear before the trend for LTCP; the main combustion regime will appear past the trend of $\mathrm{LTCM}_{\mathrm{M}}$.

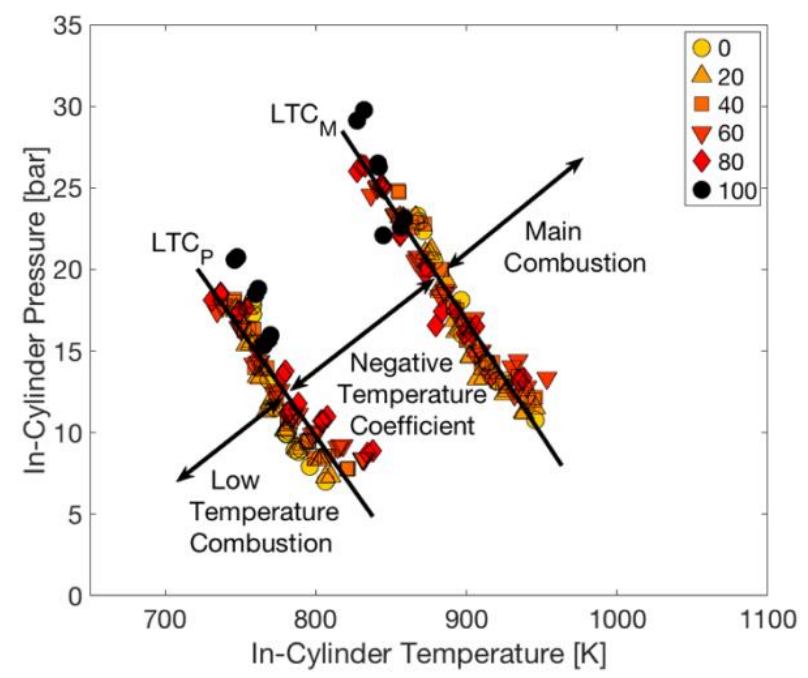

Figure 13: $L T C_{P}$ and $L T C_{M}$ with respect to octane number into the pressure-temperature diagram.

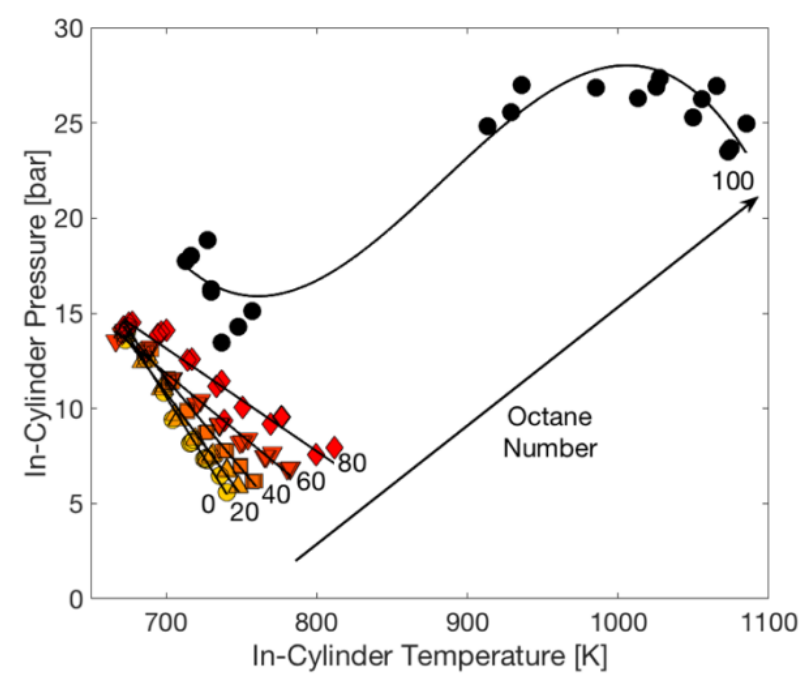

Figure 14: Start of combustion in low temperature combustion $\left(S O C_{L}\right)$ with respect to octane number, into the pressure-temperature diagram.

With respect to the $\mathrm{ON}$, results for $\mathrm{SOC}_{\mathrm{L}}$ and $\mathrm{SOC}_{\mathrm{M}}$ into pressure-temperature diagrams are presented in Figures 14 and 15, respectively. Figure 14 shows that SOC $_{\mathrm{L}}$ temperature points range from 650 to $800 \mathrm{~K}$ and from 5 to 15 bar in pressure for $\mathrm{ON}$ from 0 to 80 . Linear trends for these $\mathrm{ON}$ are seen in the pressuretemperature diagram where the curves converge towards a single point corresponding to the lowest intake temperature used (ambient temperature). The ON scale moves in sensitivity from this single point with the linear trend for the highest ON (80) going towards the highest temperature. Finally, for higher ON (i.e.PRF100), the non-linear trend clearly deviates from the other trends. At low intake temperature, the short deviation is due to a weak low temperature heat release, and at high intake temperatures, the huge deviation is due to the lack of low temperature heat release. It is likely that as soon as the low temperature heat release disappears, $\mathrm{SOC}_{\mathrm{L}}$ begins to deviate. Such a deviation might occur for PRF higher than 80 , as the negative temperature coefficient domain is quite fixed and the $\mathrm{SOC}_{L}$ trend for PRF80 (Figure 11) indicates a crossing point with the LTCP trend at the highest intake temperatures tested. 


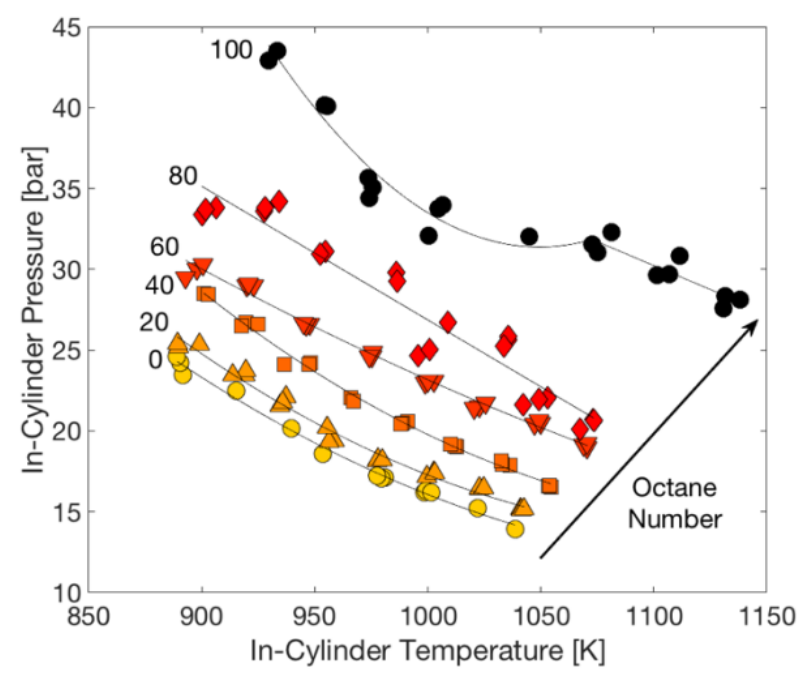

Figure 15: Start of combustion for main combustion (SOCM) with respect to octane number into pressure-temperature diagram.

Figure 15 shows that $\mathrm{SOC}_{\mathrm{M}}$ points are distributed over pressure and temperature with distinctly parallel linear trends. The higher the $\mathrm{ON}$, the higher pressure and temperature required to display the main combustion; moreover, the range expands with the increase in ON. For instance, $\mathrm{SOC}_{M}$ for PRF0 is in the 15 to 25 bar pressure range, and in the 900 to $1050 \mathrm{~K}$ temperature range, while $\mathrm{SOC}_{\mathrm{M}}$ for PRF100 is in the 30 to 45 bar pressure range and in the 950 to $1150 \mathrm{~K}$ temperature range. Finally, pressuretemperature diagrams with an $\mathrm{ON}$ scale for both $S_{C O}$ and $S_{M} C_{M}$ will help to assess the $\mathrm{ON}$ of any practical fuels. It is worth noting that $\mathrm{SOCM}$ for PRFs depend on $\mathrm{SOC}_{\mathrm{L}}$; and $\mathrm{SOC}_{\mathrm{L}}$ provides a temperature boost which helps $\mathrm{SOC}_{\mathrm{M}}$ autoignition. For this reason, rating $\mathrm{ON}$ for fuels without a low temperature heat release stage is questionable.

\section{Low temperature heat release fraction}

PRFs are prone to low temperature heat releases and this exothermic portion of the combustion is known to assist the main combustion. Characterizing the ratio of energy released during the low temperature combustion regime, with respect to the total energy release by the combustion, seems to be of major importance for rating ON. For this reason, experimental heat release rates for all the PRFs were further analyzed to assess that ratio. Results are presented in Figure 16 with respect to the intake temperature and the $\mathrm{ON}$.

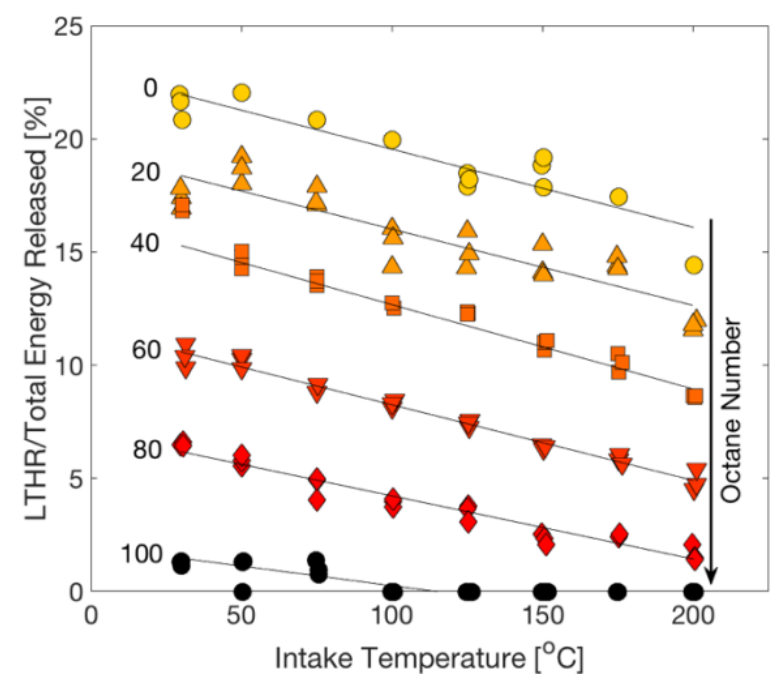

Figure 16: Ratio between energy released during low temperature combustion regime over total energy released by combustion as a function of intake temperature and $O N$.

The ratio between energy released as part of the low temperature combustion regime and the total energy released by the combustion reduces linearly with increased intake temperature. This ratio also decreases with the $\mathrm{ON}$, and the trends with respect to intake temperature are almost equally distributed over the entire ON scale. The chart in Figure 16 provides additional analysis of the $\mathrm{ON}$ of practical fuels, together with pressure-temperature diagrams discussed in the previous section.

\section{Application with practical fuels}

The goal of the second part of this study is to apply the octane scale developed for describing the combustion behavior of practical fuels in HCCI conditions. Two fuels for advanced combustion engines (FACE), representatives of practical fuels, were selected and tested [26]. Those two fuels (FACE I and FACE J), are low octane number gasoline-like fuels; their properties are given in Table 2. Experiments were performed using the same protocol as the PRFs described earlier. Combustion behavior for each practical fuel was analyzed in the required compression ratio chart, the pressuretemperature diagrams and the fraction of low temperature heat release chart. Assessment of the ON, with respect to each approach, will be discussed following analysis of the combustion behavior. 


\begin{tabular}{lcc}
\hline \hline Fuel & FACE I & FACE J \\
\hline RON & 70.15 & 73.8 \\
MON & 69.5 & 70.1 \\
S & 0.65 & 3.7 \\
Density (g/L) & 697 & 742 \\
Molar mass (g/mol) & 97.2 & 101.7 \\
H/C & 2.264 & 1.916 \\
n-paraffins (\%vol) & 14.39 & 31.64 \\
iso-paraffins (\%vol) & 74.54 & 33.64 \\
cyclo-paraffins (\%vol) & 3.30 & 2.29 \\
aromatics (\%vol) & 1.15 & 31.69 \\
olefins (\%vol) & 6.35 & 0.60 \\
\hline
\end{tabular}

\section{Required compression ratio}

The required compression ratio for FACE I and FACE $J$ with respect to intake temperature was investigated first. Results are presented in Figure 17 for both fuels with the octane scale designed earlier. The combustion behavior of those two fuels is analyzed below; ON rating will be discussed later.

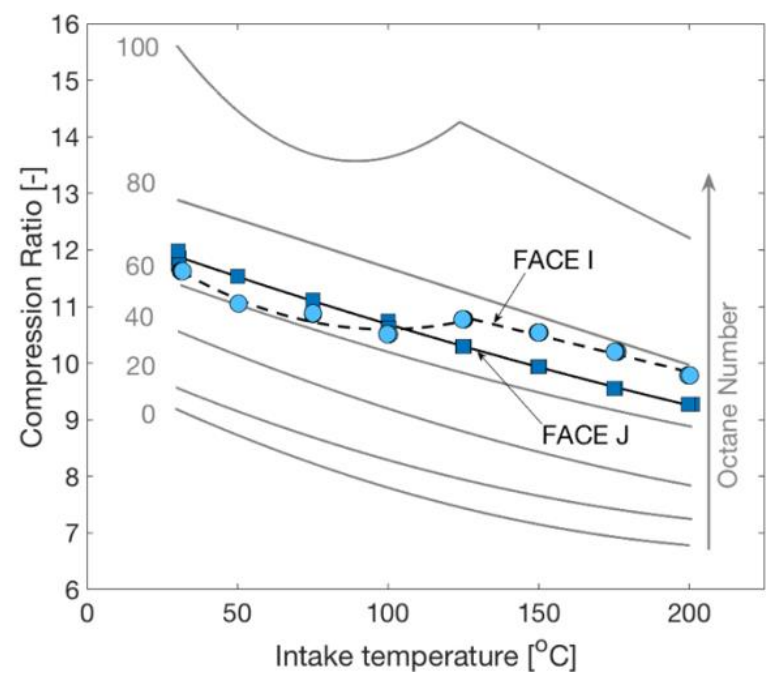

Figure 17: Compression ratio required with respect to intake temperature for FACE I and FACE J. Grey solid lines correspond to ON scale.

FACE I and FACE J displayed distinct combustion behavior, while they shared very similar RON and MON. First, FACE I required a lower compression ratio than FACE $J$, then, for higher intake temperatures, the opposite occurred. The trend for these two fuels emphasizes that RON and MON cannot be used to characterize HCCI combustion. The required compression ratio for FACE J combustion monotonically decreased with the rise of intake temperature. Moreover, the trend matches a second order fitting curve which evolved in parallel between the ON 60 trend and the ON 80 trend. This trend means that the ON of FACE J should remain fixed and low temperature heat release should occur over the range of the sampled intake temperature. The occurrence of low temperature heat release was confirmed by observing heat release rate traces for FACE $J$ in Figure 19. For FACE I, a trend for the required compression ratio, similar to that of isooctane, was observed, meaning that the $\mathrm{ON}$ for FACE I in HCCI conditions changed over the range of intake temperature. A fixed $\mathrm{ON}(\sim 60)$ was achieved for the intake temperature from $25{ }^{\circ} \mathrm{C}$ to $100{ }^{\circ} \mathrm{C}$. A higher compression ratio was then required, and finally, the compression ratio decreased linearly. The ON for FACE I appeared to range from 60 to 80 . The trend for FACE I (with respect to this discussion, and made with PRF100) indicates that low temperature heat release should be present at least until $100{ }^{\circ} \mathrm{C}$ and then it disappears. However, the heat release rate traces for FACE I in Figure 18 show the occurrence of low temperature heat release even beyond $100{ }^{\circ} \mathrm{C}$ and that low temperature heat release disappears only at the highest intake temperature used. Therefore, the change observed cannot be entirely attributed to the presence or absence of low temperature heat release, rather it indicates that a lack of low temperature heat release can be expected. However, the origin of this change could come from the multiple components in FACE I (seven different components), and the fact that some of them might interfere during the transition from $100{ }^{\circ} \mathrm{C}$ to $125{ }^{\circ} \mathrm{C}$. Further investigation will be required for a clear understanding of this change. 


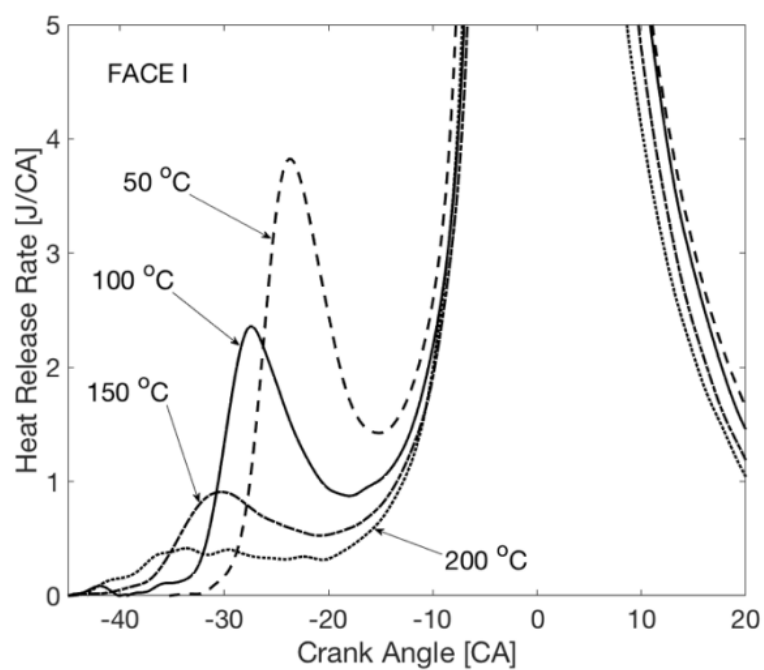

Figure 18: Heat release rate traces with respect to crank angle for FACE I as fuel and for four different intake temperatures.

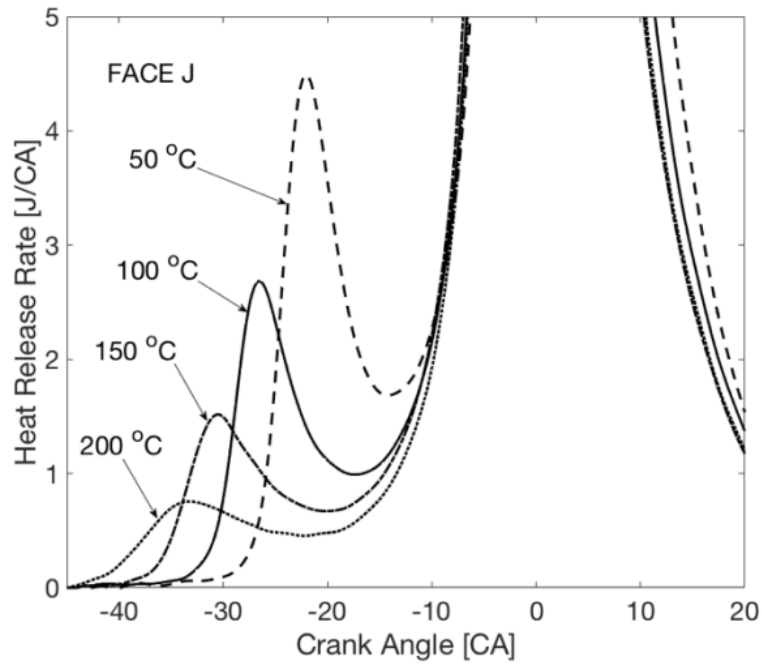

Figure 19: Heat release rate traces with respect to crank angle for FACE $J$ as fuel and for four different intake temperatures.

\section{Pressure-temperature diagrams}

To analyze the combustion behavior of FACE I and FACE J, the four key points captured from heat release rate traces were reported in their respective pressure-temperature history traces in the pressuretemperature diagram. Figures 20 and 21 show the pressure-temperature diagrams for FACE I and FACE J, respectively. Both fuels displayed behavior similar to most of the PRFs used to develop the octane scale. The three combustion regimes were clearly observed and the only minor difference was the lack of low temperature heat release detected for FACE I at $200{ }^{\circ} \mathrm{C}$ because the intensity of the low temperature combustion was too weak to be captured. To further examine the combustion of
FACE I and FACE J, the points $\mathrm{SOC}_{\mathrm{L}}, \mathrm{LTC}_{\mathrm{P}}, \mathrm{LTC}_{\mathrm{M}}$ and $\mathrm{SOC}_{\mathrm{M}}$ were split and reported in the different pressure-temperature diagrams previously developed, with their respective ON scale.

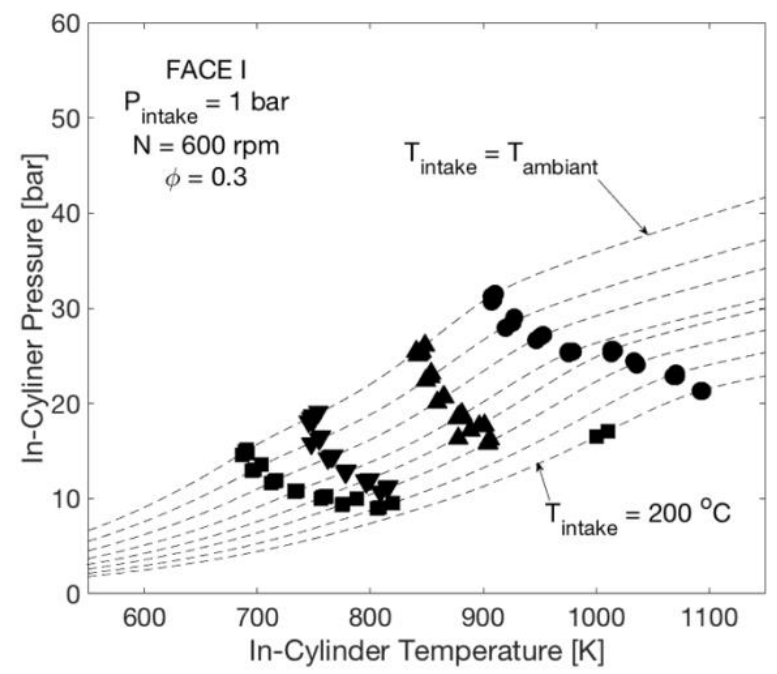

Figure 20: Pressure-temperature diagram for FACE I as fuel.

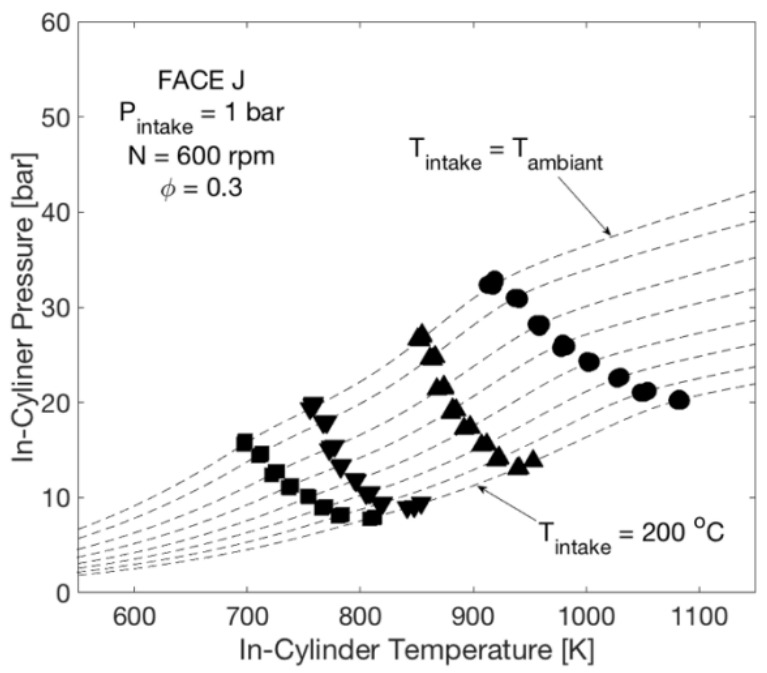

Figure 21: Pressure-temperature diagram for FACE J as fuel.

LTCP and $\mathrm{LTC}_{\mathrm{M}}$ for both FACE I and FACE J are reported in Figure 22. All these points collapsed respectively when $\mathrm{LTCP}_{\mathrm{P}}$ and $\mathrm{LTCM}_{\mathrm{M}}$ trends were extracted from the results with PRFs. No further analysis of FACE I and FACE $J$ could be made with the results in Figure 22. However, as both the LTCP and $\mathrm{LTC}_{\mathrm{M}}$ trends remained, the negative temperature coefficient domain was considered independent of the $\mathrm{ON}$ and the composition of the fuel. Those results clearly separated the different combustion regimes in terms of pressure and temperature. Similar results 
were recently observed by Somers et al. [28], with ignition delays.

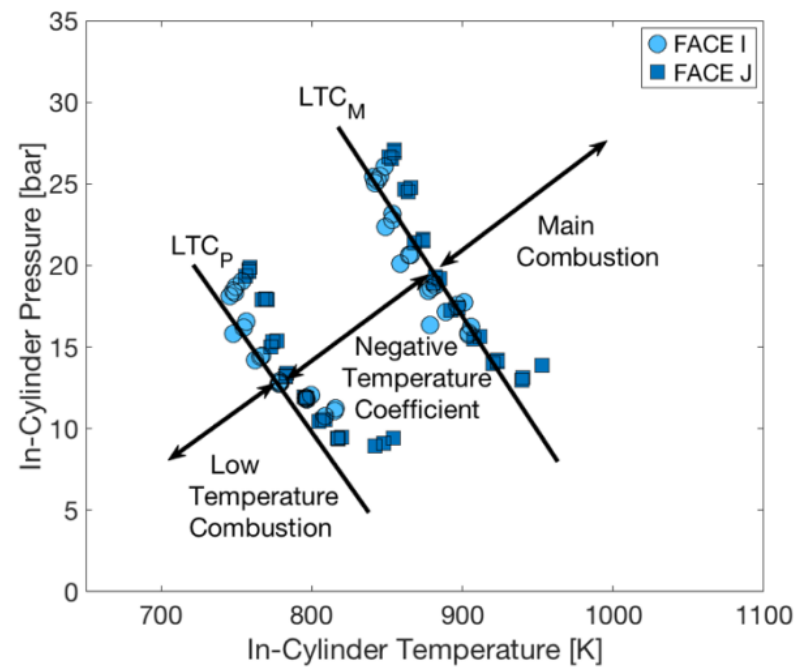

Figure 22: $L T C_{P}$ and $L T C_{M}$ for FACE I and FACE $J$ in the pressuretemperature diagram.

Results for $\mathrm{SOC}_{\mathrm{L}}$ are grouped with the respective octane scale in Figure 23. SOC $L$ for FACE I in its pressure-temperature diagram shows that the $\mathrm{ON}$ for this fuel remained around 80 for most of the intake temperature range. However, for the highest intake temperatures, the FACE I trend moved progressively away from the trend for ON 80 and finished clearly between ON 80 and 100. For FACE J, the general trend for $\mathrm{SOC}_{\mathrm{L}}$ showed an opposite trend from FACE I. Referring to ON 80, FACE J appeared more difficult to autoignite than this PRF at the lowest intake temperature, while it seemed easier to autoignite with the highest temperatures -- except at $200{ }^{\circ} \mathrm{C}$, where the trend eventually reversed. An assessment of the octane number for these two FACE fuels can be conducted based on the trends in Figure 22 and will be discussed below.

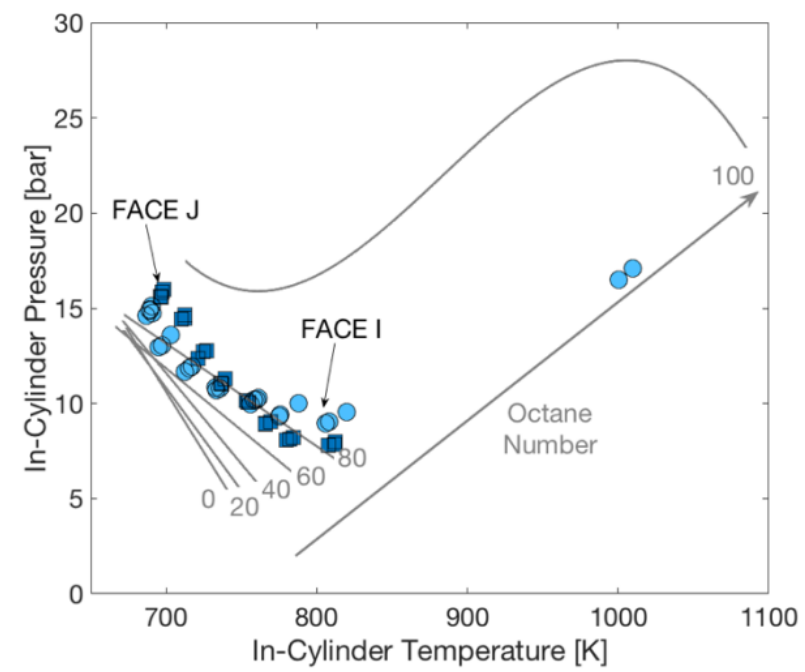

Figure 23: Start of combustion for low temperature combustion $\left(S O C_{L}\right)$ for FACE I and FACE J in the pressure-temperature diagram.

Similarly, $\mathrm{SOC}_{\mathrm{M}}$ for FACE I and FACE $\mathrm{J}$ are reported in the pressure-temperature diagram for SOCM with the ON scale in Figure 24. Both FACE I and FACE $\mathrm{J}$ were restricted by the trends of octane numbers 60 and 80, but each fuel had its own trend within this region. FACE I tended toward a fixed $\mathrm{ON}$, which increased with the intake temperature rise, while FACE $\mathrm{J}$ was inclined to get an ON that decreased slightly and then slightly increased all along the intake temperature rise. The trends observed in Figure 24 were very close to those for the required compression ratio observed in Figure 17. The pressure-temperature diagram for $\mathrm{SOC}_{M}$ therefore reproduces results similar to the required compression ratio chart. Nonetheless, the octane number rated from both approaches must be compared to confirm this conclusion. 


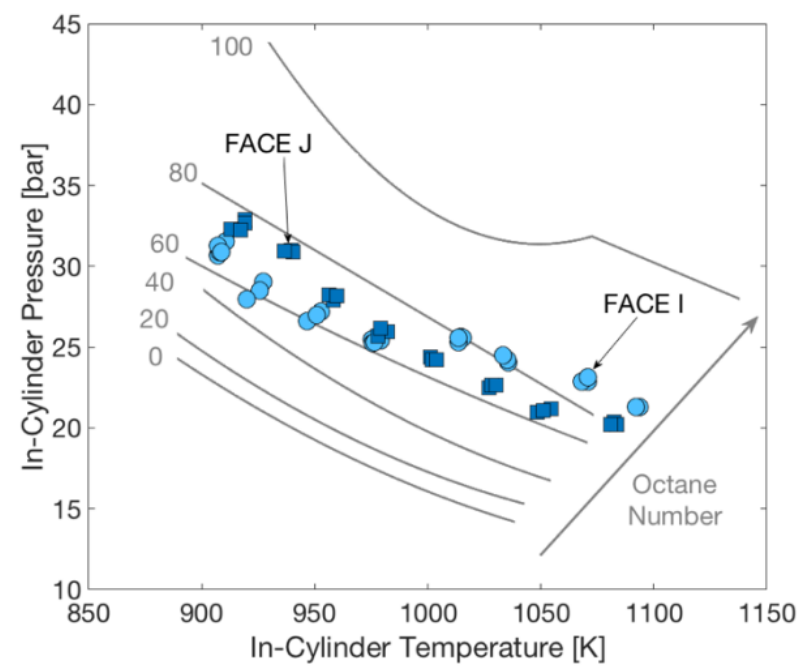

Figure 24: Start of combustion for main combustion (SOCM) for FACE I and FACE $J$ in the pressure-temperature diagram.

\section{Low temperature heat release fraction}

Finally, the fraction of low temperature heat release for both FACE I and FACE $\mathrm{J}$ is reported in its respective chart, with the octane number scale. Figure 25 shows the results. Similar to PRFs, the fraction of low temperature heat release for the two surrogates selected decreased linearly with the rise of the intake temperature. All along the intake temperature range, FACE I showed a ratio lower than that of FACE J, probably due to the lower volumetric fraction of n-paraffins in FACE I. Moreover, the linear trend for FACE I decreased faster, meaning that its $\mathrm{ON}$ increased rapidly with the rise in intake temperature, starting from an octane number slightly lower than 80 and ending with an ON greater than 80. For FACE J, the linear trend decreased in parallel to PRFs trends and a fixed constant ON could be expected. The assessment of the ON through the use of the fraction of low temperature heat release chart is discussed further in the next section.

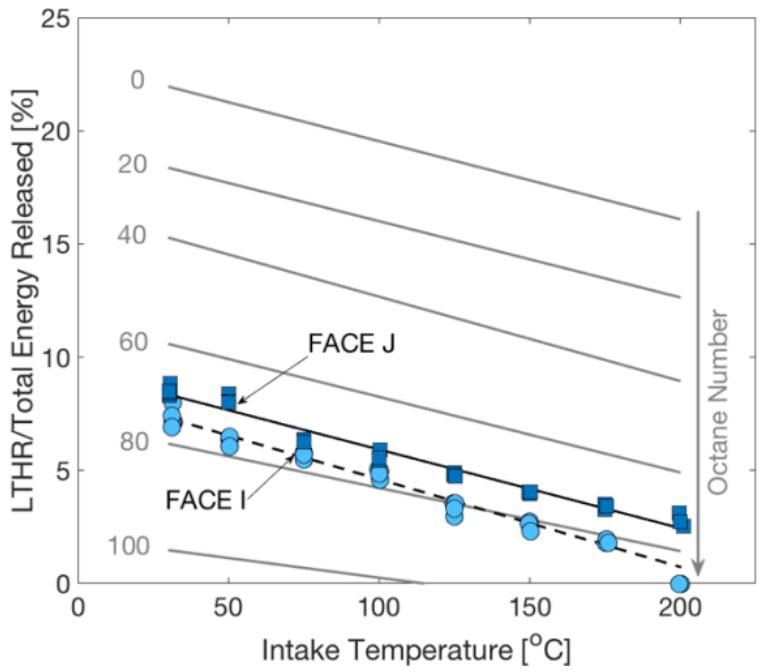

Figure 25: Ratio between energy released during low temperature combustion regime over total energy released by combustion as a function of intake temperature for FACE I and FACE J. Solid grey lines correspond to ON scale.

\section{Octane numbers of practical fuels}

All the results previously presented confirmed the combustion behavior of FACE I and FACE J with respect to the combustion behavior of PRFs under HCCI conditions. Another way to analyze those results is to assess an octane number from each $\mathrm{ON}$ scale developed. The assessed ON will indicate how practical fuels behave with respect to PRFs, and also which PRF is best for replicating specific combustion behavior of practical fuels.

An assessment of the octane numbers from the required compression ratio chart, and from the fraction of low temperature heat release chart, is made by fitting the curves into the respective chart. For each intake temperature, a correlation from PRF was performed (either between the required compression ratio or the fraction of low temperature heat release extracted from the fitting curves and the octane number), using the best-fitting polynomial trend. Then, knowing either the required compression ratio or the fraction of low temperature heat release for the practical fuel, and using the polynomial trend, an $\mathrm{ON}$ was proposed for each intake temperature. With a similar approach, assessment of the octane numbers from the pressuretemperature diagrams (i.e. from $\mathrm{SOC}_{\mathrm{L}}$ and $\mathrm{SOC}_{\mathrm{M}}$ ) was also made using the fitting curves in Figures 23 and 24 . Then, the pressure-temperature history, with 
respect to the practical fuel and the intake temperature, was used to correlate the ignition points of PRFs with the octane number. Finally, an ON was evaluated from the ignition points of the practical fuels by using the correlations obtained. Assessed ONs for FACE I and FACE $\mathbf{J}$ are shown in Figures 26 and 27 , respectively.

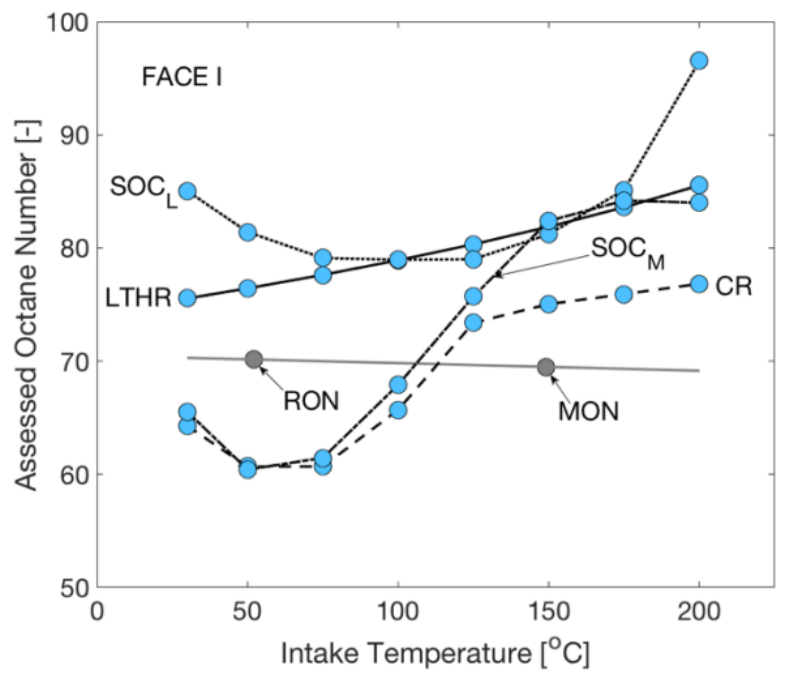

Figure 26: Assessed ONs with respect to intake temperature and combustion behavior for FACE I. Grey dots correspond to RON and $M O N$; solid grey lines corresponds to ON trend over intake temperature, referring to RON and MON.

In Figure 26, the RON and MON of FACE I (together with an octane number trend based on those two points), refer to the autoignition behavior in the SI combustion mode. Assessed octane numbers from the charts and diagrams are scattered; and they show that FACE I in HCCI combustion mode behaves very differently from SI combustion mode. Moreover, each assessed ON differs from other ONs, meaning that a single PRF cannot match the entire behavior of a practical fuel at a given temperature. Instead, one PRF per specific behavior seems required. Nonetheless, some similarities appear for ONs evaluated from $\mathrm{SOC}_{\mathrm{L}}$ and LTHR, and similar trends are present for ONs evaluated from $\mathrm{CR}$ and $\mathrm{SOC}_{\mathrm{M}}$, with a few overlapping points. For FACE J, results in Figure 27 show that the assessed ONs were also very scattered over the intake temperature sweep. However, assessed ONs for FACE J are closer to their trend based on RON and MON than assessed ONs for FACE I. However, similarities discussed above for FACE I were not observed for FACE J. As a result, a single PRF can only replicate a specific combustion behavior of a practical fuel. The reason for such a disparity in the assessed octane numbers probably occurred because practical fuels, or surrogates, are blends of multiple components which do not react at the same time during the entire HCCI combustion stroke.

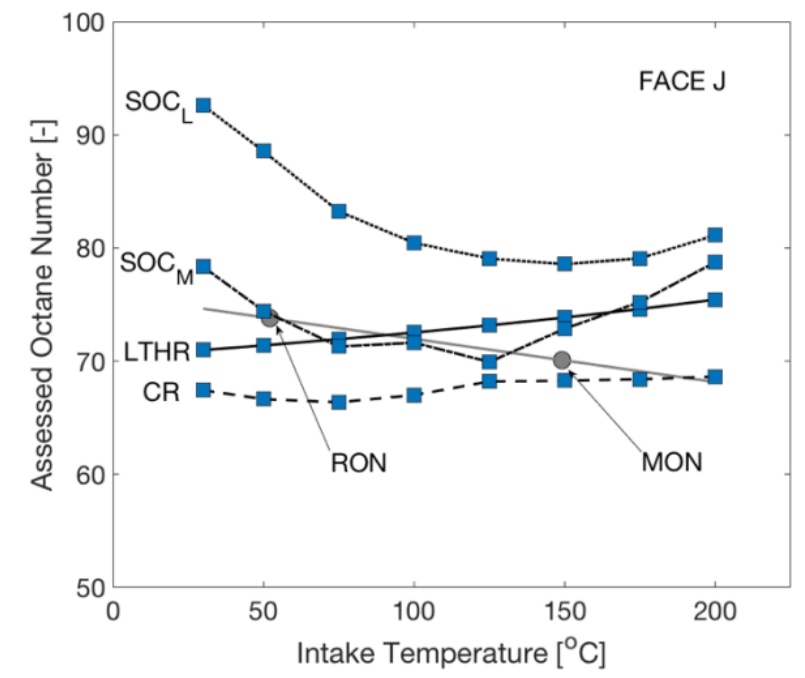

Figure 27: Assessed ONs with respect to intake temperature and combustion behavior for FACE J. Grey dots correspond to RON and $M O N$; solid grey lines corresponds to ON trend over intake temperature, referring to RON and MON.

\section{Discussion}

The approach developed for describing combustion behavior of practical fuels required two pressuretemperature diagrams and two charts. Each of those tools enabled analysis of a specific area of the combustion behavior. $\mathrm{SOC}_{\mathrm{L}}$ in the pressuretemperature diagram allows to analyze the ignition of the low temperature combustion, $\mathrm{SOC}_{\mathrm{M}}$ in the pressure-temperature diagram allows to analyze the ignition of the main combustion and the fraction of low temperature heat release allows to analyze the significance of low temperature combustion. Finally, the last chart -- the required compression ratio -provides a global analysis of the combustion behavior. In this last chart, the trends observed suggest the presence -- or the lack -- of low temperature combustion. While this is true for isooctane, FACE I did not highlight the loss of low temperature combustion immediately in heat release rate traces. In the future, other fuels which could show similar behaviors should be tested to verify the reliability of this statement, or to investigate its origins. Other post-processing should also be tested, mainly because of the sensitivity of the heat release rate to the method selected -- largely the ratio of heat capacities. The pressure-temperature diagrams, 
including octane number scales, seem to be very effective for analyzing combustion behavior of practical fuels. Nonetheless, the investigation of $\mathrm{SOC}_{\mathrm{L}}$, in particular, is slightly difficult as the trends with respect to the octane numbers collapse into a single point and the entire domain is narrow for octane numbers from 0 to 80 . As a result, rating practical fuel from this parameter may be inaccurate in this range, and even beyond 80 , since only results for $\mathrm{ON} 100$ are proposed. Moreover, the use of $\mathrm{SOC}_{\mathrm{M}}$ is also questionable because this parameter is dependent upon the $\mathrm{SOC}_{\mathrm{L}}$, since low temperature combustion induces a small rise in temperature that promotes the occurrence of the main combustion. Therefore, the use of PRFs as a reference for the development of an octane number scale may be irrelevant for describing all the fuels, especially those without low temperature combustion. This statement is even more applicable to the fraction of low temperature heat release, which is based entirely on the presence of low temperature combustion. To this end, assessment of ONs through these various pressure-temperature diagrams and charts suggests that ONs from HCCI combustion and SI combustion cannot be compared. Instead of a single octane number, multiple scattered octane numbers are required for HCCI combustion. However, ONs rated in this study from pressure-temperature diagrams should be corrected because the pressuretemperature history used involved combustion beyond the $\mathrm{SOC}_{\mathrm{M}}$ point. This change in the pressuretemperature history, and the assessment of the ONs on which it is based, induce an overestimated octane number. Instead, the firing pressure-temperature history should be replaced by a motoring pressuretemperature history; but the presence of low temperature combustion could still cause issues. Finally, these scattered octane numbers tend to further support the irrelevance of PRFs as a reference for investigating combustion behavior of practical fuels.

\section{Conclusions}

A new approach for analyzing the combustion behavior of practical fuels in HCCI combustion mode has been developed and tested. Two different charts and two pressure-temperature diagrams, including an octane number scale based on PRFs, were used to describe the combustion of practical

Page 16 of 22

$10 / 19 / 2016$ fuels. The first approach developed was the required compression ratio chart, which provides an octane number representative of the global combustion, while other charts and diagrams focused on specific areas of the combustion. $\mathrm{SOC}_{\mathrm{L}}$ and $\mathrm{SOC}_{\mathrm{M}}$ pressuretemperature diagrams in particular provide octane numbers representative of the start of combustion for low temperature combustion and for the main combustion, respectively. Finally, the fraction of low temperature heat release chart provides octane numbers representative of the low temperature combustion regime. Based on the results observed, the following conclusions were drawn:

- The required compression ratio chart is a useful tool for a quick description of the entire combustion behavior of fuels. Based on the trend obtained with respect to an intake temperature sweep, the fuel likely reveals the presence, or lack, of low temperature heat release. Further investigation is required to better understand the cause of the change in the occurring trend.

- In the pressure-temperature diagram of $\mathrm{SOC}_{\mathrm{L}}$ the ON scale collapses at the lowest intake temperature for all the PRFs, excepting PRF100, which has a distinct trend due to the lack of low temperature heat release. That condition of intake temperature makes the assessment of octane numbers difficult. With increased intake temperature, assessment of the $\mathrm{ON}$ becomes easier, because the trend for each octane number expands linearly.

- The ON scale in the pressure-temperature diagram of $\mathrm{SOC}_{\mathrm{M}}$ describes combustion behavior similar to the behavior provided by the required compression ratio chart.

- LTCP $_{P}$ and LTC $_{M}$ evolve linearly, and in parallel on the pressure-temperature diagram. Moreover, those trends are independent of the fuel so that fixed domains are defined for each combustion regime, i.e. low temperature combustion, negative temperature coefficient and the main combustion.

- The fraction of low temperature heat release decreases linearly and is equally distributed with respect to the $\mathrm{ON}$. 
- Octane numbers from HCCI combustion differ greatly from RON and MON, meaning that autoignition requires its own octane number scale, such as that proposed here.

- Octane numbers assessed for two surrogates, representative of practical fuels, are scattered with respect to intake temperature and selected approach. These results suggest that a single PRF cannot replicate the entire combustion behavior of a practical fuel. Instead, one PRF for each specific behavior is required. The octane scale based on PRFs may be irrelevant and unsatisfactory to represent autoignition of practical fuels.

In addition to the above conclusions, some perspectives are suggested:

- The ON scale in each chart and diagram was developed with six PRFs, equally distributed from 0 to 100 , but the trends suggest that intermediate PRFs between octane numbers 60 and 100 are required to refine ON scales. Also, the lack of low temperature heat release could be further investigated by determining when this part of the combustion behavior ceases.

- Improvements in the octane scale could be performed by considering a single fitting surface with all the results from PRFs, instead of the multiple fitting curves used for each PRF.

- The ON scale is still restricted from 0 to 100 . A method that avoids extrapolation and extends the scale into HCCI conditions is therefore required. Perhaps binary mixtures other than n-heptane and isooctane or ternary mixtures (which are drastically defined), should be considered, for a wider and more representative $\mathrm{ON}$ scale.

- Fuels having $\mathrm{ON}$ in the range covered by the ON scale, but without the low temperature combustion regime, should be tested to confirm the relevance of the approach developed in the present study.

- Engine speed and equivalence ratio were kept fixed in the present study but both parameters are expected to have a significant impact on the results. Future studies should consider their respective effects in the various proposed diagrams and charts.

\section{References}

1. Kalghatgi, G.T., "Fuel/Engine Interactions (Warrendale: SAE International, 2014)," ISBN 978-0-7680-6458-2, 2014.

2. Wang, Z., Liu, H., and Reitz, R.D., "Knocking combustion in spark-ignition engines," Prog. Energy Combust. Sci. 61:78112, 2017, doi:10.1016/j.pecs.2017.03.004.

3. ASTM International, "Standard Test Method for Research Octane Number of SparkIgnition Engine Fuel - D2699 - 08," ASTM Int.

4. ASTM International, "Standard Test Method for Motor Octane Number of Spark-Ignition Engine Fuel - D2700 - 08," ASTM Int.

5. Kalghatgi, G.T., "Auto-Ignition Quality of Practical Fuels and Implications for Fuel Requirements of Future SI and HCCI Engines," SAE Tech. Pap. Ser. 2005-010239, 2005, doi:10.4271/2005-01-0239.

6. Hauber, J., Huber, K., and Nell, R., "New GKI - Gasoline Knock Index for Rating of Fuel's Knock Resistance on an Upgraded CFR Test Engine," SAE Tech. Pap. 2018-011743, 2018, doi:10.4271/2018-01-1743.

7. Shibata, G. and Urushihara, T., "Autoignition characteristics of hydrocarbons and development of HCCI fuel index," SAE Int. 2007(724):776-790, 2007, doi:10.4271/2007-01-0220.

8. Truedsson, I., Cannella, W., Johansson, B., and Tuner, M., "Development of New Test Method for Evaluating HCCI Fuel Performance," SAE Tech. Pap. 2014-012667, 2014, doi:10.4271/2014-01-2667.

9. Kalghatgi, G., Babiker, H., and Badra, J., “A Simple Method to Predict Knock Using 
Toluene, N-Heptane and Iso-Octane Blends (TPRF) as Gasoline Surrogates," SAE Int. J. Engines 8(2), 2015, doi:10.4271/2015-010757.

10. Szybist, J.P. and Splitter, D.A., "Pressure and temperature effects on fuels with varying octane sensitivity at high load in SI engines," Combust. Flame 177:49-66, 2017, doi:10.1016/j.combustflame.2016.12.002.

11. Liu, H., Yao, M., Zhang, B., Zheng, Z., "Influence of Fuel and Operating Conditions on Combustion Characteristics of a Homogenous Charge Compression Ignition Engine," Energy \& Fuels (23):1422-1430, 2009.

12. Splitter, D., Kaul, B., Szybist, J., and Jatana, G., "Engine Operating Conditions and Fuel Properties on Pre-Spark Heat Release and SPI Promotion in SI Engines," SAE Int. J. Engines 10(3), 2017, doi:10.4271/2017-010688 .

13. Chun, K.M. and Heywood, J.B., "Estimating Heat-Release and Mass-of-Mixture Burned from Spark-Ignition Engine Pressure Data," Combust. Sci. Technol. 54:1-6:133-143, 1987, doi:10.1080/00102208708947049.

14. Splitter, D.A., Gilliam, A., Szybist, J., and Ghandhi, J., "Effects of pre-spark heat release on engine knock limit," Proc. Combust. Inst. 000:1-8, 2018, doi:10.1016/j.proci.2018.05.145.

15. Vuilleumier, D., Kim, N., Sjöberg, M., Yokoo, N., Tomoda, T., and Nakata, K., "Effects of EGR Constituents and Fuel Composition on DISI Engine Knock: An Experimental and Modeling Study," $S A E$ Tech. Pap. 2018-01-1677, 2018, doi:10.4271/2018-01-1677.

16. Szybist, J.P. and Splitter, D.A., "Understanding chemistry-specific fuel differences at a constant RON in a boosted SI engine," Fuel 217(August 2017):370-381, 2018, doi:10.1016/j.fuel.2017.12.100.
17. Gilliam, A., Splitter, D.A., Szybist, J., and Ghandhi, J., "Fuel kinetics effects on prespark heat release and engine knock limit," THIESEL 2018 Conf. 1-11, 2018.

18. Rapp, V.H., Defilippo, A., Saxena, S., Chen, J., Dibble, R.W., Nishiyama, A., Moon, A., and Ikeda, Y., "Extending Lean Operating Limit and Reducing Emissions of Methane Spark-Ignited Engines Using a MicrowaveAssisted Spark Plug," 2012(x), 2012, doi:10.1155/2012/927081.

19. Sjöberg, M. and Dec, J.E., "Combined Effects of Fuel-Type and Engine Speed on Intake Temperature Requirements and Completeness of Bulk-Gas Reactions for HCCI Combustion Reprinted From : Homogeneous Charge Compression Ignition Engines 2003," SAE Tech. Pap. Ser. 200301-3173, 2003.

20. Truedsson, I., Tuner, M., Johansson, B., and Cannella, W., "Pressure Sensitivity of HCCI Auto-Ignition Temperature for Primary Reference Fuels," SAE Int. J. Engines 201201-1128 5(3), 2012, doi:10.4271/2012-011128 .

21. Truedsson, I., Tuner, M., Johansson, B., and Cannella, W., "Pressure Sensitivity of HCCI Auto-Ignition Temperature for Gasoline Surrogate Fuels," SAE Int. J. Engines 201301-1669 5(3):2012-01-1128, 2013, doi:10.4271/2012-01-1128.

22. Masurier, J., Waqas, M., Sarathy, M., and Johansson, B., "Autoignition of isooctane beyond RON and MON conditions," SAE Tech. Pap. 2018-01-1254, 2018, doi:10.4271/2018-01-1254.

23. Masurier, J.-B., Altoaimi, O., Mohammed, A., and Waqas, M., "Combustion Behavior of n-Heptane, Isooctane, Toluene and Blends under HCCI Conditions in the PressureTemperature Diagram," SAE Tech. Pap. 2018-01-1684, 2018, doi:10.4271/2018-011684.

24. Gatowski, J.A., Balies, E.N., Chun, K.M., 
Nelson, F.E., Ekchian, J.A., and Heywood, J.B., "Heat Release Analysis of Engine Pressure Data," SAE Tech. Pap., 1984.

25. Chen, J.S., Litzinger, T.A., and Curran, H.J., "Lean oxidation of iso-octane in the intermediate temperature regime at elevated pressures," Combust. Sci. Technol. 156(16):49-79, 2000, doi:10.1080/00102200008947296.

26. Cannella, W., Foster, M., Gunter, G., and Leppard, W., "Face Gasolines and Blends With Ethanol: Detailed Characterization of Physical and Chemical Properties," Cordinating Res. Counc. Inc. (July), 2014.

27. Javed, T., Ahmed, A., Lovisotto, L., Issayev, G., Badra, J., Sarathy, S.M., and Farooq, A., "Ignition studies of two low-octane gasolines," Combust. Flame 185:152-159, 2017 , doi:10.1016/j.combustflame.2017.07.006.

28. Somers, K.P., Cracknell, R.F., and Curran, H.J., "A chemical kinetic interpretation of the octane appetite of modern gasoline engines," Proc. Combust. Inst. 000:1-8, 2018, doi:10.1016/j.proci.2018.05.123.

\section{Contact Information}

Jean-Baptiste Masurier

jeanbaptiste.masurier@kaust.edu.sa

\section{Acknowledgments}

The research reported in this publication was supported by funding from King Abdullah University of Science and Technology (KAUST).

The authors also thank Adrian I. Ichim and Riyad H. Jambi for their technical support.

\section{Definitions/Abbreviations}

\%vol

ATDC
Volumetric fraction

After top dead center
CR

FACE

g/L

g/mol

HCCI

HTHR

J/CA

K

$\mathbf{L} / \mathbf{h}$

$\operatorname{LTC}_{M}$

LTCP $_{P}$

LTHR

$\mathbf{m m}$

MON

${ }^{\circ} \mathrm{C}$

ON

PRF

RON

$\mathbf{S}$

SI

slpm

$\mathrm{SOC}_{L}$

$\operatorname{SOC}_{M}$
Crank angle

Cubic centimeter

Cooperative fuel research

Compression ratio

Fuel for advanced combustion engines

Gram per liter

Gram per mole

Homogeneous charge compression ignition

High temperature heat release

Joule per crank angle

Kelvin

Liter per hour

Minimum between peak of low temperature heat release and peak of main combustion

Peak of low temperature heat release

Low temperature heat release

Millimeter

Motor octane number

Celsius degree

Octane number

Primary reference fuel

Research Octane Number

Sensitivity

Spark ignition

Standard liter per minute

Start of combustion for low temperature combustion

Start of combustion for main combustion 


\section{Appendix 1 - Data post-processing}

The present appendix summarizes the post-processing used by the authors which led to the results observed and discussed. The Appendix is organized to emphasize the different steps of the post-processing, from the acquired data (pressure traces) to the final results (heat release rate trace). It is worth noting that each cycle is analyzed individually with respect to the entire below described process and then, an average is made based on 200 consecutive cycles for discussion.

\section{In-cylinder pressure pegging}

In-cylinder pressure is acquired using an AVL QC34D piezo-electric pressure transducer with a resolution of 0.2 crank angles. With this kind of pressure transducer, the in-cylinder pressure recorded is relative with a sensorspecific reference. A normal quantification of the in-cylinder pressure requires converting the pressure recorded with the help of an absolute pressure transducer by applying a process called pegging. Here, an AVL LP11DA absolute pressure transducer set in the intake port of the engine is used for the pegging. The absolute in-cylinder pressure is therefore obtained through the below equation and assuming that the intake pressure equals the incylinder pressure on a range of 10 crank angles before the intake valve closure (IVC).

$$
P_{\text {cyl }}=P_{\text {cyl raw }}-\int_{I V C-10}^{I V C} P_{\text {cyl raw }}+\int_{I V C-10}^{I V C} P_{\text {intake }}
$$

\section{Volume calculation}

As part of the post-processing, the volume of the combustion chamber with respect to the crank angle $(\theta)$ is required. First, the following characteristics of the engine must therefore be known: Stroke (S), Bore (B), Connecting rod length $(\mathrm{L})$ and Compression ratio $\left(\mathrm{R}_{\mathrm{c}}\right)$. Second, some geometric parameters based on those characteristics are calculated:

$$
\begin{aligned}
& \text { Displaced volume: } V_{d}=\frac{\pi}{4} B^{2} S \\
& \text { Crank radius: } A=\frac{S}{2} \\
& \text { Clearance volume: } V_{c}=\frac{V_{d}}{R_{c}-1}
\end{aligned}
$$

Finally, based on the crank-silver, the position of piston with respect to the crank angle can be calculated according to the below equation, and then the in-cylinder volume.

$$
\begin{gathered}
X=A \cos \left(\theta \frac{\pi}{180}\right)+\sqrt{L^{2}-\left(A \sin \left(\theta \frac{\pi}{180}\right)\right)^{2}} \\
V_{c y l}=\frac{\pi}{4} B^{2}(L+A-X)+V_{c}
\end{gathered}
$$




\section{Temperature calculation}

The air/fuel mixture is assumed to be a perfect gas into the combustion chamber. Accordingly, the ideal gas law can be used to estimate the in-cylinder temperature. Here, the below equation is used assuming that we know the conditions at the intake valve closing.

$$
T_{c y l}=\frac{P_{c y l} V_{c y l}}{P_{I V C} V_{I V C}} T_{I V C}
$$

While $\mathrm{P}_{\text {IVC }}$ and $\mathrm{V}_{\mathrm{IVC}}$ are easy to obtain, a good assessment of $\mathrm{T}_{\mathrm{IVC}}$ is required. In the present post-processing, this temperature is taken from the temperatures measured in the intake and in the exhaust, and with a balance using the fraction of residuals. In the present case, the fraction of residuals is assumed to be directly the inverse of the compression ratio $\left(\chi_{\text {res }}=1 / R_{c}\right)$.

$$
T_{I V C}=T_{\text {intake }}\left(1-\chi_{\text {res }}\right)+T_{\text {exhaust }} \chi_{\text {res }}
$$

\section{Heat release rate calculation}

Finally, the heat release rate is obtained from the sum of the apparent heat release rate, the heat transfer losses, the blow-by losses and the crevices losses. The last two terms in this equation do not contribute so much on the heat release rate and they are therefore neglected.

$$
\left.\left.\left.\left.\frac{d Q}{d \theta}=\frac{d Q}{d \theta}\right)_{\text {apparent }}+\frac{d Q}{d \theta}\right)_{\text {heat transfer }}+\frac{d Q}{d \theta}\right)_{\text {blow-by }}+\frac{d Q}{d \theta}\right)_{\text {crevices }}
$$

The first term is expressed from the well-known equation which involves the in-cylinder pressure, the volume and the ratio of the heat capacities. In-cylinder pressure and volume are already available at this step and the ratio of the heat capacities $(\gamma)$ is based on both the mixture into the combustion chamber and the estimated in-cylinder temperature. In other words, $\gamma$ is computed from the equation which uses JANNAF coefficients and those coefficients are selected based on the mixture. For a first run, the mixture is assumed to be air, fuel and residuals and once a first complete heat release rate has been calculated, $\gamma$ is recalculated considering the formation of complete products.

$$
\left.\frac{d Q}{d \theta}\right)_{\text {apparent }}=\frac{\gamma}{\gamma-1} P_{c y l} \frac{d V_{c y l}}{d \theta}+\frac{1}{\gamma-1} V_{c y l} \frac{d P_{c y l}}{d \theta}
$$

The second term, the heat transfer, is expressed from the below equation. The temperature of the wall is fixed at $100{ }^{\circ} \mathrm{C}$ and $S_{\text {exchange }}$ corresponds to the surfaces involved in the heat transfer (piston, cylinder head and liner) with respect to the crank angle. Finally, the heat transfer coefficient $h$ is calculated from the correlation proposed by Woschni.

$$
\left.\frac{d Q}{d \theta}\right)_{\text {heat transfer }}=h S_{\text {exchange }}\left(T_{\text {cyl }}-T_{\text {wall }}\right)
$$

The correlation proposed by Woschni expresses the heat transfer coefficient as below, where the term $\varpi$ corresponds to the average cylinder gas velocity. The coefficients $C_{0}, C_{1}$ and $C_{2}$ are tuned from a motoring cycle such that the final heat release rate approximates zero with respect to the crank angle. Finally, $\overline{S_{p}}$ is the mean piston speed and $P_{m o t}$ is estimated here from the compression stroke part of the cycle (before any ignition). 


$$
\begin{gathered}
h=C_{0} B^{-0.2} P_{c y l}{ }^{0.8} T_{c y l}{ }^{-0.55} \varpi^{0.8} \\
\varpi=C_{1} \overline{S_{p}}+C_{2} \frac{V_{d} T_{I V C}}{P_{I V C} V_{I V C}}\left(P_{c y l}-P_{m o t}\right)
\end{gathered}
$$

From now, a first heat release rate can be calculated. By integrating this first heat release, the heat capacities ratio is recalculated and the final heat release rate is obtained. The results are finally extracted from all those traces after an average of 200 cycles. 